\title{
Transfer of persistence from fixed-ratio barpress training to runway extinction
}

\author{
TOM McCULLER, PAUL T. P. WONG, and ABRAM AMSEL \\ The University of Texas at Austin, Austin, Texas 78709
}

\begin{abstract}
Two experiments were performed to investigate transfer of persistence across different situations and response topographies. Experiment I demonstrated that FR 100 barpress training increased resistance to runway extinction as compared with a control. In Experiment II, resistance to extinction in the runway was systematically and positively related to terminal ratio requirements of prior barpress training.
\end{abstract}

There is some evidence that training which results in persistent responding in one situation may increase persistence in other situations. It has been demonstrated, for examplc (Brown \& Wagner, 1964), that partial rein. forcement training in rats increases resistance to punishment, and that partial punishment training increases resistance to appetitive extinction. In domestic chicks, prior punishment of approach to an imprinting stimulus results in increased resistance to extinction of a food rewarded running response (Amsel, Wong, \& Scull, 1971). Similarly, prior coerced-approach training in rats increases subsequent resistance to extinction of a food rewarded running response (Wong, 1972a, b). Although transfer of persistence has been shown across different situations, involving different motivational states, the experiments have usually involved the same response system, a locomotive approach response. The possible exception is an experiment by Ross (1964). Here direct approach responding was still involved but there was a demonstrated transfer of persistence from jumping a gap or climbing to running in an alley.

Results obtained from transfer experiments involving different instrumental response systems - different in the sense that one of the responses is not a direct goal approach response - are less clear-cut. Lewis (unpublished experiment cited in Spear \& Pavlik, 1966) and Wenrich, Eckman, Moore, and Houston (1967) found increased resistance to extinction of continuously rewarded barpressing after partially rewarded runway training. However, Rashotte (1971), in two experiments, failed to confirm these earlier findings. These conflicting results may be related to differences in the shaping procedures used and particularly to the ease with which shaping was accomplished. Often the shaping procedure consists of several levels of approximation to the final barpress. The rat first is rewarded for moving closer to the lever, then for orienting toward it, then for any

Supported by Grant GB-14990X from the National Science Foundation. The authors are grateful to Nelson Donegan for his assistance in collecting the data.

The second author is now at Trent University, Petersborough. Ontario, Canada.

Requests for reprints should be sent to Abram Amsel, Department of Psychology. The University of Texas at Austin, Austin, Texas 78709 . physical contact with it, and so on. Under these conditions, error responses and experience with frustrative nonreward would be less than in a shaping procedure that consists of fewer steps. In any event, shaping inevitably involves rewarded and nonrewarded approaches to the foodcup which defines partial-reinforcement training for that approach response. Depending on the shaping procedure, such training may produce persistence in all groups and mask the effects of the differential persistence training received in the runway. We decided, therefore, to test transfer of persistence in the other direction; to manipulate the amount of persistence training in the box and test for transfer to the runway, since runway training for the rat is much less subject to a shaping procedure which involves inconsistent reward, and is less likely to override any differential effects of the leverbox training.

It is well established that resistance to extinction in barpressing is positively related to terminal ratio requirements (e.g., Boren, 1961). The first experiment was a demonstration that rats trained to a high fixed ratio of leverpress responding are more resistant to extinction than controls simply placed in the box for equal periods of time. The second experiment was designed to demonstrate a positive relationship between resistance to extinction of a continuously rewarded running response and the terminal ratio requirement in barpress training. Greater resistance to extinction of the running response following higher terminal ratios would reflect transfer of persistence not only across situations but also across substantially different response systems. So, the strategy of this research was to (a) demonstrate, first, that training to high responding-to-reinforcement ratios in a box affects subsequent alley extinction compared to no such training, and (b) by parametric manipulation of the terminal barpress-to-reinforcement ratio, establish that the size of this ratio, and not some other factor, determines the degree of transfer of persistence from leverbox training to runway extinction.

\section{EXPERIMENT I}

The first experiment was a simple two-group investigation of transfer of persistence from FR 100 barpress 


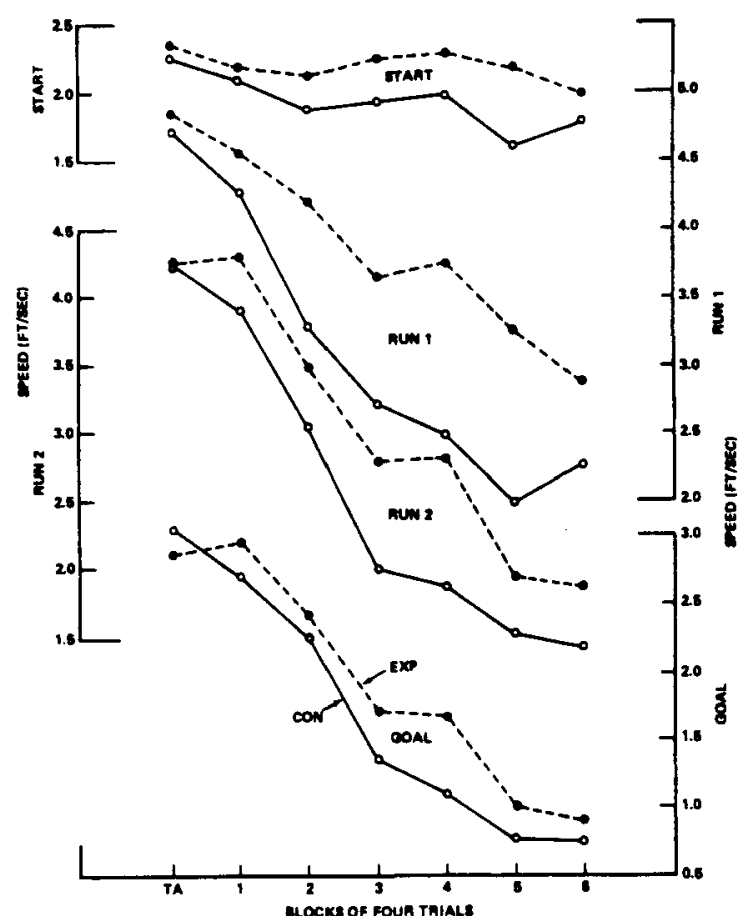

Figure 1. Data from Experiment I, showing terminal acquisition level (TA) in the runway and extinction performance over 4 runway segments. EXP $=$ FR 100.

training to extinction of a continuously rewarded response in a runway.

\section{Method}

Subjects. The subjects were 20 experimentally naive male albino rats, purchased from Holtzman Company, Madison, Wisconsin. They were approximately 90 days old at the beginning of the experiment. Throughout the experiment, all subjects were housed in individual cages with water continuously available.

Apparatus. The black wooden runway was $190 \mathrm{~cm}$ long, $7.6 \mathrm{~cm}$ wide, and $10.2 \mathrm{~cm}$ high, covered with clear Plexiglas. The runway was connected to a $15.2 \mathrm{~cm} \times 7.6 \mathrm{~cm} \times 10.2 \mathrm{~cm}$ gray startbox through a clear Plexiglas door. A black sheet metal retrace door was situated $45.7 \mathrm{~cm}$ from the goal end of the runway. Three time measures in addition to a start-time measure were provided by photoelectric circuitry. They covered $1 \mathrm{ft}$ $(30.5 \mathrm{~cm}), 3 \mathrm{ft}(91.5 \mathrm{~cm})$, and $1 \mathrm{ft}(30.5 \mathrm{~cm})$, respectively. All four times were converted to speeds for analysis.

The two barpress chambers were 8.2 in. $(21 \mathrm{~cm})$ wide, 9 in. $(23 \mathrm{~cm})$ long, and $7.8 \mathrm{in} .(20 \mathrm{~cm})$ high. On one end wall of each chamber, a 2 in. $(5.1 \mathrm{~cm}) \times 2$ in. $\times 2$ in. recessed foodcup was centrally mounted 1.25 in. $(2.8 \mathrm{~cm})$ from the floor. Lehigh Valley retractable bars were mounted about 1 in. $(2.5 \mathrm{~cm})$ from the right side of the foodcup and 1.25 in. $(2.8 \mathrm{~cm})$ from the floor. The bar, on each trial, extended into a metal bar guard, so that when it was extended only the top of the bar was exposed, in order to control the topography of the barpress response. The chambers were housed in lightproof, sound-attenuated boxes. All controlling and recording functions were done by a Grason-Stadler SCAT system.

Design and procedure. Fourteen days prior to experimental training, all subjects were placed on a food deprivation schedule of $12 \mathrm{gm}$ of Wayne Lab Chow per day. The subjects were randomly assigned to one of two groups (10 subjects/group). Reward in both the runway and the barpress chamber consisted of one 300-mg Noyes food pellet. Runway training was always one trial per day. A 60 -sec timeout preceded each barpress training session during which the bar was not extended. After each subject produced the criterion number of barpresses, a food pellet was delivered and the bar was simultaneously withdrawn for $60 \mathrm{sec}$. Daily barpressing sessions were terminated after four rewards were delivered. Daily running order of the subjects was randomized. Approximately $30 \mathrm{~min}$ following the last training trial, all subjects received $12 \mathrm{~g}$ of food less the amount received in the training apparatus.

In Phase 1, the subjects in the experimental (EXP) group were shaped to 10 barpresses per reward over 12 consecutive days. Each of the subjects in the control (CON) group was yoked with a subject in the EXP group and was placed in a conditioning chamber, with the bar lever retracted, for the same time that the yoked subject took to complete his daily session. During this period, Group CON never received food in the conditioning chamber, although they received four $300-\mathrm{mg}$ Noyes food pellets with their daily ration in the home cage to control for experience with the food pellets used as reward. Approximately $2 \mathrm{~min}$ following removal from the conditioning chamber, each subject was given a rewarded trial in the runway. The same experimenter removed each subject from its home cage and placed it into the runway or into the conditioning chamber, depending on the type of trial conducted.

In Phase 2, runway training was discontinued. In the case of Group EXP, after 16 trials on a given ratio the number of barpresses necessary to obtain reward was increased by 10 until a terminal criterion of 100 barpresses per reward was reached, following which 48 additional trials were run on this terminal ratio. Group CON was placed in the control chamber throughout this phase as in the previous one.

In Phase 3 all subjects were given 12 additional rewarded runway trials, followed by 24 runway extinction trials. There was no barpress training during this phase. During extinction, if a subject took more than $60 \mathrm{sec}$ to run any runway segment, the experimenter placed him in the goalbox. All subjects were confined in the goalbox for 20 sec on each trial.

\section{Results}

Figure 1 presents mean speeds for terminal acquisition and throughout extinction training for all four measures. There were no significant differences between groups in rewarded runway performance. Group EXP ran faster throughout extinction in the Start, Run 1 , and Run 2 measures, producing a groups main effect in each measure ( $F s=10.09,13.85,10.91, \mathrm{df}=1 / 18, \mathrm{p}<.01)$. The Groups by Trial Blocks interaction was significant only in the start $(F=2.29, \mathrm{df}=6 / 108, \mathrm{p}<.05)$ and Run 1 measures $(F=3.00$, df $=6 / 108, p<.01)$. The graph also shows superior performance by Group EXP in the goal measure; however, the difference was not statistically significant.

\section{EXPERIMENT II}

The results of Experiment I clearly demonstrate that barpressing with a fairly large terminal ratio increases resistance to extinction in the runway. The next question is: Does barpressing with different terminal ratios systematically produce different degrees of persist- 
ence in the runway? The present experiment addresses itself to that question.

\section{Method}

Subjects. The subjects were 44 experimentally naive male Holtzmann rats. They were approximately 90 days of age at the beginning of the experiment. All subjects were housed in individual cages with water continuously available.

Apparatus. The runway was the same one used in Experiment I. The three barpressing chambers were identical to the ones used in Experiment I.

Design and procedure. Fourteen days prior to experimental training, the subjects were placed on food deprivation. All subjects received $12 \mathrm{gm}$ per day of Wayne Lab Chow. As in Experiment I, running order was randomized each day. The daily ration was given approximately $30 \mathrm{~min}$ after the last subjects received treatment. Runway training was always conducted one trial per day; barpress training was always four trials per day. All trials were reinforced with one 300-mg Noyes pellet except during extinction training. The subjects were randomly assigned to one of four groups (11 subjects/group).

In Phase 1 all subjects received 40 trials in the runway. ${ }^{1}$ Runway training was continued in Phase 2; however, approximately 2 min preceding the daily runway trials, each subject received four barpress shaping trials in one of the barpress chambers. Four subjects from each group received all training in Chamber 1, four subjects from each group in Chamber 2, and 3 subjects in Chamber 3. All subjects were shaped to give 10 barpresses per trial over 6 consecutive days, and this was followed by 2 more days ( 8 more trials) on FR 10 . All barpress trials were preceded by a 60 -sec period during which the bar was withdrawn. A barpress trial was initiated by the extension of the bar. After the tenth barpress, the bar was withdrawn and a food pellet was simultaneously delivered to the foodcup.

In Phase 3, runway training was discontinued and 200 barpress trials were conducted, 4 trials per day. One group (FR 10) continued barpress training throughout with a response criterion of ten barpresses per trial. For the other three groups, after each 16 trials the barpress criterion was increased by 10 . After each group reached its terminal response criterion, the criterion remained unchanged for the remainder of the 200 trials. For one group (FR 40) the terminal criterion was 40 barpresses per trial, for another (FR 80) the terminal criterion was 80 barpresses per trial, and for the last group (FR 120) the terminal criterion was 120 barpresses per trial.

In Phase 4 runway training was reinstated and barpress training discontinued. Twelve rewarded runway trials were followed by 32 extinction trials, still at one trial per day. During extinction, if the subject took more than $60 \mathrm{sec}$ to run any segment it was placed in the goalbox. All subjects were confined in the goalbox for $20 \mathrm{sec}$.

\section{Results}

There were no significant differences between groups during runway acquisition training.

While the same general pattern occurred in all three segments during extinction, the groups differed significantly only in the start segment and total runway speeds. Figure 2 presents mean speed data for these two measures for all groups. The extinction rates for the start measure were slower for the groups trained on larger terminal ratios, as shown by a significant Groups by Trial Blocks interaction $(F=3.29$, $\mathrm{df}=24 / 320$, $\mathrm{p}<.001)$. There was also in the start measure a significant groups main effect $(F=3.68, \mathrm{df}=3 / 40, \mathrm{p}<.025)$.
Combining all measure into a single total runway speed, the Groups by Trial Blocks interaction was significant $(\mathrm{F}=2.58, \mathrm{df}=24 / 320, \mathrm{p}<.001)$, indicating slower extinction rates in the runway following barpress training with larger terminal ratios. The orderly nature of the results with parametric variation of the FR terminal ratio lends confidence to the statement that there is transfer of persistence from fixed-ratio barpress training to runway extinction.

\section{DISCUSSION}

The present findings of transfer of persistence across different situations can be interpreted in a number of ways. Since transfer experiments are within-subjects procedures, and inasmuch as the Skinner box and the runway are distinctly different in physical appearance, mediated generalization (Amsel, 1967) suggests itself as a possibility. Stated in terms of the language of frustration theory (Amsel, 1958, 1962), nonreward following reward produces primary frustration $\left(R_{F}\right)$ which becomes conditioned to stimuli that immediately precede or accompany the frustration reaction. $R_{F}$ is therefore the UCS for the conditioning of frustration to these stimuli, the conditioned frustration with its feedback stimulus being designated $\mathrm{r}_{\mathrm{F}}-\mathrm{s}_{\mathrm{F}}$. The frustra-

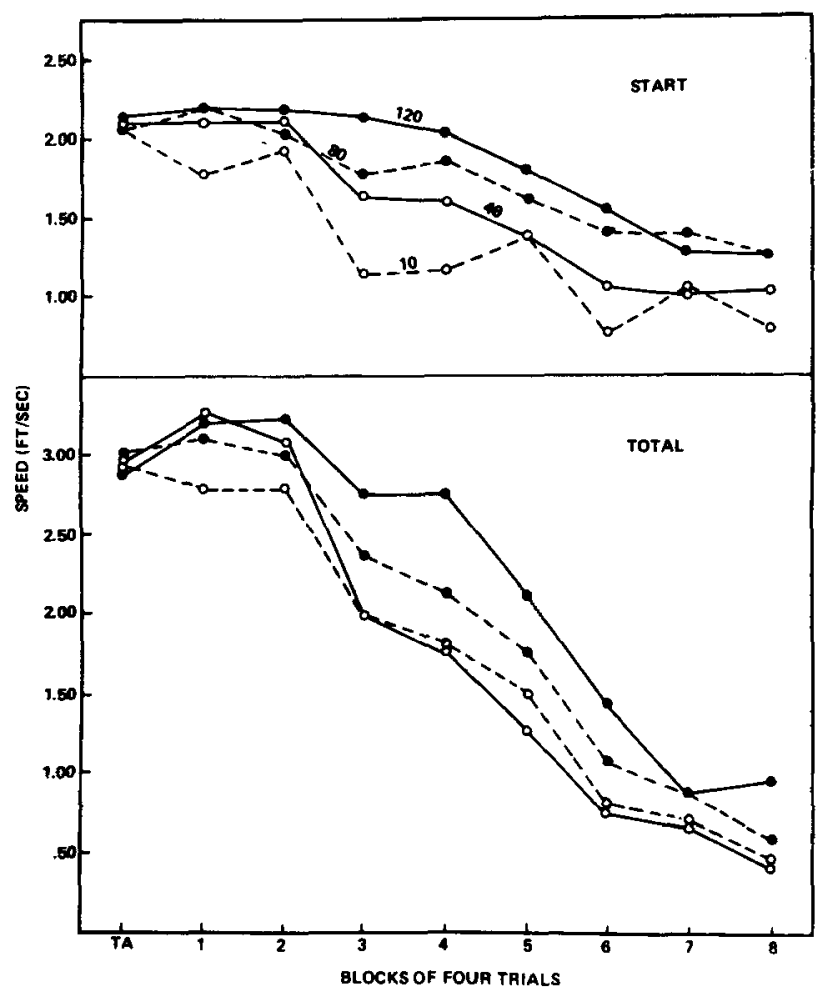

Figure 2. Data from Experiment II, showing terminal acquisition level (TA) and extinction performance for the four groups with varying terminal ratios of barpresses to reward. The start measure and overall (Total) alley measure are shown. 
tion theory of persistence holds that the conditioning of an instrumental response to $\mathrm{s}_{\mathrm{F}}$ is the mechanism of persistence and that subsequent presence of the internal $\mathrm{s}_{\mathrm{F}}$ (i.e., in extinction of a subsequent response) should elicit the previously conditioned instrumental response through mediated generalization. The following considerations argue that the transfer of persistence in our present experiments was mediated by the $\mathrm{r}_{\mathrm{F}}-\mathrm{sF}_{\mathrm{F}}$ mechanism.

First, extinction may be considered the extreme case of a ratio schedule, one involving an infinitely long ratio. Second, both long-ratio schedules and extinction are known to produce aggressive behavior (Azrin, Hutchinson, \& Hake, 1966; Gallup, 1965, Knutson, 1970) and escape behavior (Adelman \& Maatsch, 1956; Azrin, 1961; Thompson, 1964, 1965), and these behaviors have been attributed to either the frustrative nonreward or emotionality present in both cases. Third, increasing ratio requirements systematically increases aggressive behavior (e.g., Cherek \& Pickens, 1970) and self-imposed extinction (Azrin, 1961), implicating again some degree and kind of emotionality associated with the higher ratio requirements. Since the intensity of $\mathrm{rF}-\mathrm{SF}$ is assumed to be directly related to the magnitude of primary frustration, one has to conclude that the instrumental response has been conditioned to a broader range of $s_{F}$ intensities, and with stronger $s_{F}$ intensities, with higher ratio requirements. Given the finding that specific intensities of $s_{F}$ can be conditioned to an instrumental response (Traupmann, Amsel, \& Wong, 1973), the prediction is that extinction performance in the runway should be positively related to the length of terminal ratio in barpress training, a result obtained in Experiment II.

However, the foregoing does not account for transfer across response systems. If transfer of persistence is due mainly to mediated generalization of the response previously evoked by $\mathrm{s}_{\mathrm{F}}$, then during runway extinction one should observe the emergence in the alley of a response like barpressing (e.g., Rashotte \& Amsel, 1968). However, instead of such "regression" we observed an increased persistence in the running response. In terms of our introductory considerations, it is possible to argue that the greater persistence in the runway with higher terminal ratios may be the result of conditioning foodcup approaches to $\mathrm{s}_{\mathrm{F}}$. When barpress training goes to high ratios, rats often approach and inspect the empty foodcup before they complete the required responses. In this sense, they have been partially reinforced for approach to the foodcup. However, if the transfer is mainly one of foodcup approach, then the transfer might be expected to be strongest in the goal segment of the alley, which, as we have seen, is not the case.

In addition to, or instead of, mediated generalization as an explanation of transfer effects, transfer may depend on common external stimuli that precede runway trials and barpress trials. In our experiments the rat was always removed from his home cage by the same experimenter directly preceding both kinds of trials. If the tendency to respond persistently or the elicitation of $\mathrm{r}_{\mathrm{F}}-\mathrm{sF}_{\mathrm{F}}$ was conditioned to this set of stimuli, the transfer would be a case of primary stimulus generalization rather than mediated generalization, and the transfer of persistence effect would be greater in the start segment of the runway.

\section{REFERENCES}

Adelman, H. M., \& Maatsch, J. L. Learning and extinction based upon frustration, food reward, and exploratory tendency. Journal of Experimental Psychology, 1956, 52, 311-315.

Amsel, A. The role of frustrative nonreward in noncontinuous reward situations. Psychological Bulletin, 1958,55, 102-119.

Amsel, A. Frustrative nonreward in partial reinforcement and discrimination learning: Some recent history and a theoretical extension. Psychological Review, 1962, 69, 306-328.

Amsel, A. Partial reinforcement effects on vigor and persistence. In Spence, K. W., \& Spence, J. T. (Eds.), The psychology of learning and motivation, 1967, Vol. 1. New York: Academic Press.

Amsel, A., Wong, P. T. P., \& Scull, J. Transfer of persistence in the domestic chick: Imprinting, punishment, and resistance to extinction of a food-rewarded running response. Psychonomic Science, 1971, 25, 174-176.

Azrin, N. H. Time-out from positive reinforcement. Science, $1961,133,382-383$.

Azrin, N. H., Hutchinson, R. R., \& Hake, D. F. Extinctioninduced aggression. Journal of the Experimental Analysis of Behavior, 1966, 9, 191-204.

Boren, J. J. Resistance to extinction as a function of the fixed ratio. Journal of Experimental Psychology, 1961, 61. 304-308.

Brown, R. T., \& Wagner, A. R. Resistance to punishment and extinction following training with shock or nonreinforcement. Journal of Experimental Psychology, 1964, 68, 503-507.

Cherek, D. R.. \& Pickens, R. Schedule-induced aggression as a function of fixed-ratio value. Journal of the Experimental Analysis of Behavior, 1970, 14, 309-312.

Gallup, G. G., Jr. Aggression in rats as a function of frustrative nonreward in a straight alley. Psychonomic Science, 1965, 3, 99-100.

Knutson, J. F. Aggression during the fixed-ratio and extinction components of a multiple schedule of reinforcement. Journal of the Experimental Analysis of Behavior, 1971, 13, 221-232.

Rashotte, $M$. E. Influence of partial reinforcement of running on the extinction of continuously reinforced barpressing in rats. Psychonomic Science, 1971, 25, 145-147

Rashotte, M. E., \& Amsel, A. Transfer of slow-response rituals to the extinction of a continuously rewarded response. Journal of Comparative and Physiological Psychology, 1968, $66,432-443$.

Ross, R. R. Positive and negative partial-reinforcement extinction effects carried through continuous reinforcement changed motivation, and changed response. Journal of Experimental Psychology, 1964, 68, 492-502.

Spear, N. E., \& Pavlik, W. B. Percentage of reinforcement and reward magnitude effects in a T-maze: Between and within subjects. Journal of Experimental Psychology, 1966, 71, 521-528.

Thompson, D. M. Escape from $\mathbf{S}^{D}$ associated with fixed-ratio reinforcement. Journal of the Experimental Analysis of Behavior, 1964, 7, 1-8.

Thompson, D. M. Time-out from fixed ratio reinforeement: A systematic replication. Psychonomic Science, 1965, 2, 109-110.

Traupmann, K. L., Amsel, A., \& Wong, P. T. P. Persistence early and late in extinction as a function of number of continuous reinforcements preceding partial reinforcement training. Animal Learning \& Behavior, 1973, 1, 212-222.

Wenrich, W. W., Eckman, G. E., Moore, M. T., \& Houston, D. F. A transresponse effect of partial reinforcement. Psychonomic Science, 1967, 9, 247-248. 
Wong, P. T. P. Coerced approach to shock and resistance to punishment suppression and extinction in the rat. Journal of Comparative and Physiological Psychology, 1971a, 75, 82-91.

Wong, P. T. P. Coerced approach to shock, punishment of competing responses and resistance to extinction in the rat. Journal of Comparative and Physiological Psychology, $1971 b, 76,275-281$

\section{NOTES}

1. The second experiment was run a little differently from the first, exploratory experiment. In the first experiment, box training to FR 10 was initiated in the first phase along with CRF runway training at one trial a day. The second phase was box training only, to a terminal ratio: of FR 100, and the third phase was $C \pi F$ runway training and extinction only, at one trial a day. The procedure in the second, parametric investigation was like the first except that there were 4 phases, the first consisting of 40 CR F runway trials at one trial a day, the second, third, and fourth phases being like the first, second, and third of Experiment I. The procedure in Experiment II promotes nondifferenment $I$. The procedure in Experiment II promotes nondifferen-
tial and stable runway performance in all four groups in the first two phases, introduces the variable of terminal ratio size in Phase 3 in the absence of runway training, and tests for the effect of the Phase 3 treatment in the runway in Phase 4 in the absence of leverbox training.

(Received for publication June 15, 1974.

Revision received July $31,1975$. 